\title{
Role of the long cytoplasmic domain of the SIV Env glycoprotein in early and late stages of infection
}

\author{
Andrei N Vzorov*1, Armin Weidmann¹,4, Natalia L Kozyr², \\ Vladimir Khaoustov ${ }^{3}$, Boris Yoffe $^{3}$ and Richard W Compans ${ }^{1}$
}

\author{
Address: ${ }^{1}$ Dept. of Microbiology and Immunology and Emory Vaccine Center, Emory University, Atlanta, GA, USA, ${ }^{2}$ Dept of Medicine and Emory \\ Vaccine Center, Emory University, Atlanta, GA, USA, ${ }^{3}$ Dept of Medicine, Baylor College of Medicine, Houston, TX, USA and ${ }^{4}$ MorphoSys AG, \\ Martinsried/Planegg, Germany \\ Email: Andrei N Vzorov* - avzorov@emory.edu; Armin Weidmann - Armin.Weidmann@morphosys.com; \\ Natalia L Kozyr - nkozyr@rmy.emory.edu; Vladimir Khaoustov - adimirk@bcm.tmc.edu; Boris Yoffe - byoffe@bcm.tmc.edu; \\ Richard W Compans - compans@microbio.emory.edu \\ * Corresponding author
}

Published: | 4 December 2007

Retrovirology 2007, 4:94 doi:10.1/86/1742-4690-4-94

This article is available from: http://www.retrovirology.com/content/4/I/94

(C) 2007 Vzorov et al; licensee BioMed Central Ltd.

This is an Open Access article distributed under the terms of the Creative Commons Attribution License (http://creativecommons.org/licenses/by/2.0), which permits unrestricted use, distribution, and reproduction in any medium, provided the original work is properly cited.
Accepted: I4 December 2007
Received: 20 September 2007

\begin{abstract}
Background: The Env glycoproteins of retroviruses play an important role in the initial steps of infection involving the binding to cell surface receptors and entry by membrane fusion. The Env glycoprotein also plays an important role in viral assembly at a late step of infection. Although the Env glycoprotein interacts with viral matrix proteins and cellular proteins associated with lipid rafts, its possible role during the early replication events remains unclear. Truncation of the cytoplasmic tail (CT) of the Env glycoprotein is acquired by SIV in the course of adaptation to human cells, and is known to be a determinant of SIV pathogenicity.
\end{abstract}

Results: We compared SIV viruses with full length or truncated $(T)$ Env glycoproteins to analyze possible differences in entry and post-entry events, and assembly of virions. We observed that early steps in replication of SIV with full length or T Env were similar in dividing and non-dividing cells. However, the proviral DNA of the pathogenic virus clone SIVmac239 with full length Env was imported to the nucleus about 20-fold more efficiently than proviral DNA of SIVmac239T with T Env, and 100-fold more efficiently than an SIVmac I8T variant with a single mutation A239T in the SU subunit and with a truncated cytoplasmic tail (CT). In contrast, proviral DNA of SIVmacl 8 with a full length CT and with a single mutation A239T in the SU subunit was imported to the nucleus about 50-fold more efficiently than SIVmac $8 \mathrm{~T}$. SIV particles with full length Env were released from rhesus monkey PBMC, whereas a restriction of release of virus particles was observed from human 293T, CEMxI74, HUT78 or macrophages. In contrast, SIV with T Envs were able to overcome the inhibition of release in human HUT78, CEMxI74, 293T or growth-arrested CEMxI74 cells and macrophages resulting in production of infectious particles. We found that the long CT of the Env glycoprotein was required for association of Env with lipid rafts. An Env mutant C787S which eliminated palmitoylation did not abolish Env incorporation into lipid rafts, but prevented virus assembly.

Conclusion: The results indicate that the long cytoplasmic tail of the SIV Env glycoprotein may govern post-entry replication events and plays a role in the assembly process. 


\section{Background}

The Env glycoproteins of retroviruses play an important role in the initial steps of infection involving the binding to cell surface receptors and entry by membrane fusion. The Env glycoprotein also plays an important role in viral assembly at a late step of infection. There is evidence for intracellular interaction of Env with the matrix protein [14], and the Env glycoprotein directly influences the site of release of virus particles in polarized epithelial cells [5]. The cytoplasmic tail of the Env glycoprotein is required for such interactions and has effects on Env incorporation and infectivity $[3,6]$. In addition, removal of the cytoplasmic domain can increase the expression of Env on the surface of infected cells, its incorporation into VLPs or membrane vesicles [7-9] and the fusion activity of the Env glycoprotein $[10,11]$.

SIV and HIV Env glycoproteins contain a relatively long cytoplasmic domain (150-200 amino acids) compared with most other retroviral Env glycoproteins. Nonhuman primates in Africa that are natural hosts for SIV appear to be disease resistant when infected with SIV, whereas nonnatural Asian macaque hosts such as rhesus macaques exhibit progressive CD4+-T-cell depletion and AIDS [1214]. When SIV strains were passaged on human cell lines they frequently acquired a premature stop codon and expressed a truncated Env glycoprotein that lacks all but approximately 20 amino acids of the cytoplasmic domain [15-18]. However, molecular clones of SIV with truncated Env only establish transient infection in rhesus macaques [19]. Variants with truncated Env are commonly isolated from both types of infected monkeys $[15,17,19]$. However, variants of HIV with truncated Env are rarely isolated from infected patients, even though HIV-1 infected patients can harbor viruses with truncated Env that are able to mediate CD4-independent infection of CD8+ cells [20].

By budding through lipid rafts in T-cells, HIV and SIV selectively incorporate raft marker proteins and exclude non-raft proteins [21]. The depletion of cholesterol from viral membranes inactivates and permeabilizes HIV and SIV virions [22]. These results indicate a critical role of lipid rafts in the biology of these viruses. It was reported that HIV budding in primary macrophages occurs through the exosome release pathway [23]. A non-pathogenic molecular clone SIVmac1A11 closely related to SIVmac239 but with a truncated Env, which was isolated from an infected rhesus macaque, was able to replicate in monkey macrophages, rhesus PBMC, and human T-cells. However, a pathogenic clone of SIVmac239 was restricted for replication in monkey macrophages and human $\mathrm{T}$ cells $[16,17,24]$. These results indicated that virus replication capacity in different cell lines does not correlate with in vivo virulence.

In the present study we have compared molecularly cloned SIV isolates with sequence differences in the Env glycoprotein, acquired during adaption to human T cells, to investigate the effects of the long cytoplasmic tail of the Env glycoprotein on early steps of replication as well as assembly of SIV. We further compared the replication of these viruses in dividing and non-dividing cells.

\section{Results \\ Properties of SIV variants}

In the present study we compared SIVmac239 and several SIVmac239 derivates with mutations in the Env glycoprotein resulting from adaptation to cell culture (Fig. 1). SIVmac18 with a single mutation A239T in the SU subunit and a full length cytoplasmic tail, SIVmac18T with a single mutation A239T in the SU subunit and with a truncated cytoplasmic tail, and SIVmac239T with a truncated cytoplasmic tail were described previously [25]. SIVmac239 exhibits a low level of Env incorporation, resistance to neutralization by antibodies and slow replication in human CEMx174 and rhesus monkey PBMC (Table 1). SIVmac18T, a variant with a truncated Env isolated by adaptation to human HUT78 cells, exhibits a high level of Env incorporation, sensitivity to neutralization and rapid replication in human HUT78, CEMx174 and rhesus monkey PBMC. SIVmac18, the corresponding virus with a full length Env, also demonstrated a high level of Env incorporation and sensitivity to neutralization, but slow replication.

Table I: Phenotypic properties of SIV.

\begin{tabular}{|c|c|c|c|c|}
\hline \multirow[t]{2}{*}{ Virus } & \multicolumn{4}{|c|}{ Phenotypic properties I } \\
\hline & Env incorporation & length of Env CT & sensitivity to neutralization & replication ${ }^{2}$ \\
\hline SIVmac239 & low & full & low & slow \\
\hline SIVmac239T & high & truncated & low & slow \\
\hline SIVmacl8 & high & full & high & slow \\
\hline SIVmacl8T & high & truncated & high & rapid \\
\hline
\end{tabular}

Iproperties of SIV variants were determined previously (Vzorov et al., 2005)

${ }^{2}$ levels of replication were determined in HUT78, CEMxI74 cells, and rhesus monkey PBMC 


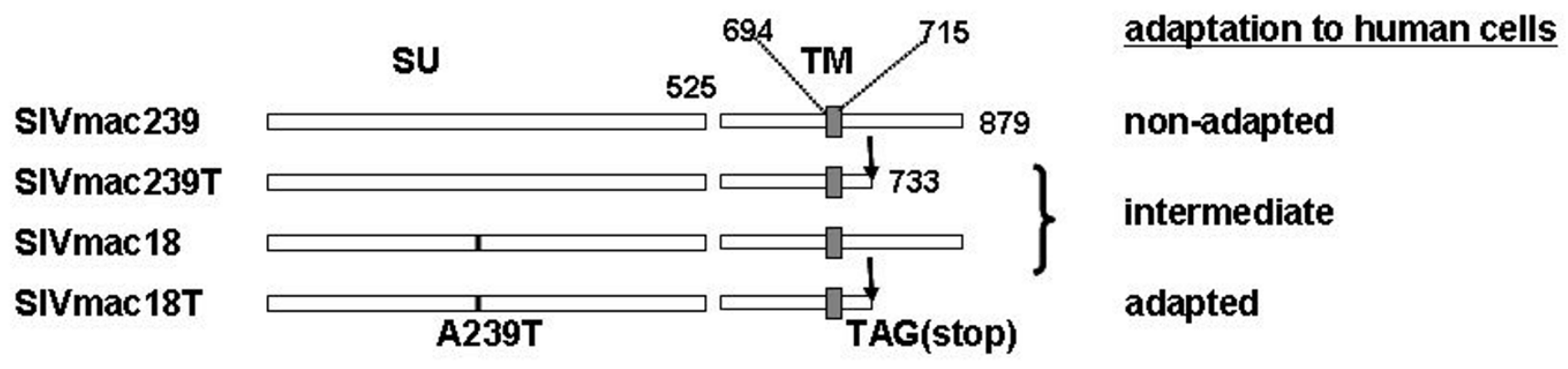

\section{Figure I}

Schematic representation of envelope gene products of cloned SIV adapted or not adapted to human cells. SIVmac239 has a full length I64 amino acid cytoplasmic tail (CT) [64]. The 239T construct has a truncated CT of I8 amino acids. A site-specific $C$ to $T$ mutation present in the 239T env gene changed a CAG glutamine codon at position 734 to a TAG termination codon. SIVmac 18T contains a single amino acid substitution A239T in the SU domain designated I8 [25]. Numbers represent amino acid residues. Shaded boxes represent the hydrophobic transmembrane-spanning regions.

\section{SIV post-entry replication in dividing vs. non-dividing cells}

The entry mechanisms appear to be similar for $\mathrm{T}$ and $\mathrm{M}$ tropic SIV viruses [26]. They utilize similar receptors and coreceptors for membrane fusion and are able to use the endocytic pathway [27]. The early events of SIV infection include the attachment, entry, uncoating and transport of the genome to the transcription site, formation of the preintegration complex (PIC), and import into the nucleus. Not much is known about the composition of reverse transcription complexes, particularly during the early steps after internalization. After virus-cell fusion, viral RNA and associated proteins are released into the cytoplasm and may interact with the cytoskeleton [28]. To investigate the possible effect of Env glycoprotein differences on early steps of replication in dividing and nondividing cells we used an indicator cell line assay with human epithelial HeLa cells expressing CCR5 and CD4. The nuclear activation of a galactosidase indicator assay does not require late events such as virion protein expression, virus particle assembly, or virion maturation [29]. To compare infection in dividing or non-dividing MAGIR5 cells, we used SIV viruses and Ebola GP pseudotyped HIV at a similar titer determined as described in Methods, to infect about 30 to 50 dividing cells. Non-dividing cells were arrested in the $\mathrm{G}_{1}$-S phase of the cell cycle by using aphidicolin, an inhibitor of eukaryotic DNA polymerase $\alpha$. [30]. After 3 days of infection the numbers of infected cells were compared in dividing and non-dividing cells (Fig. 2). Similar levels of blue staining nuclei were observed in dividing and non-dividing cells in all samples, including cells infected by Ebola GP pseudotyped HIV. The results indicate that import of proviral DNA of SIV and HIV to the nucleus in dividing and non-dividing cells occurs by mechanisms that are independent of the differences in sequence of Env. As an alternative method, we also used real-time PCR, which is a more accurate method for comparison of early steps in replication (during $24 \mathrm{~h}$ post transfection) of viruses with different replication rates. We used the same amounts of input virus with an equal infectious index (IU/ng) 3 IU/ng for each virus as described in Methods. A high number of copies of proviral DNA was determined in nuclei isolated from rhesus monkey PBMC infected by SIV with full length Env, and a significantly lower amount in nuclei infected by SIV with truncated Env at 24 hr post infection: about $1.39 \times$ $10^{6}$ DNA copies infected by SIVmac239 and about $1.3 \times$ $10^{6}$ DNA copies infected by SIVmac18, or about $4 \times 10^{4}$ DNA copies infected by SIVmac239T and about $5.3 \times 10^{3}$ DNA copies infected by SIVmac18T (Fig. 3). We obtained similar results with other tested cell lines CEMx174, HUT78, rhesus monkey macrophages (not shown); with increased multiplicity of infection for SIV viruses with truncated Env we observed increased replication levels. The ratio of infectious indices was 3 IU/ng of SIVmac239 to $9 \mathrm{IU} / \mathrm{ng}$ of SIVmac18 to $60 \mathrm{IU} / \mathrm{ng}$ of SIVmac239T to $450 \mathrm{IU} / \mathrm{ng}$ of SIVmac18T, or differences of 3 to 20 or 150 fold, respectively. We determined about $2 \times 10^{5}$ copy numbers per $1 \times 10^{6}$ dividing or non-dividing CEMx174 cells for all viruses after PCR amplification (Fig. 4). The amount of proviral DNA in nuclei isolated from dividing and non-dividing cells infected by SIV with full length or truncated Env was quite similar, within one PCR cycle. The results may also indicate the possible difference between DNA metabolism of SIV with full length or truncated Env by significantly higher ratio of infectious particles to proviral DNA copies of SIV with full length than with truncated Env.

Taken together, the results indicate that virus entry into cells was similar for SIV with full length or truncated Env in dividing vs. non-dividing cells. The full length Env glycoprotein exhibited a significant effect on the efficiency of 


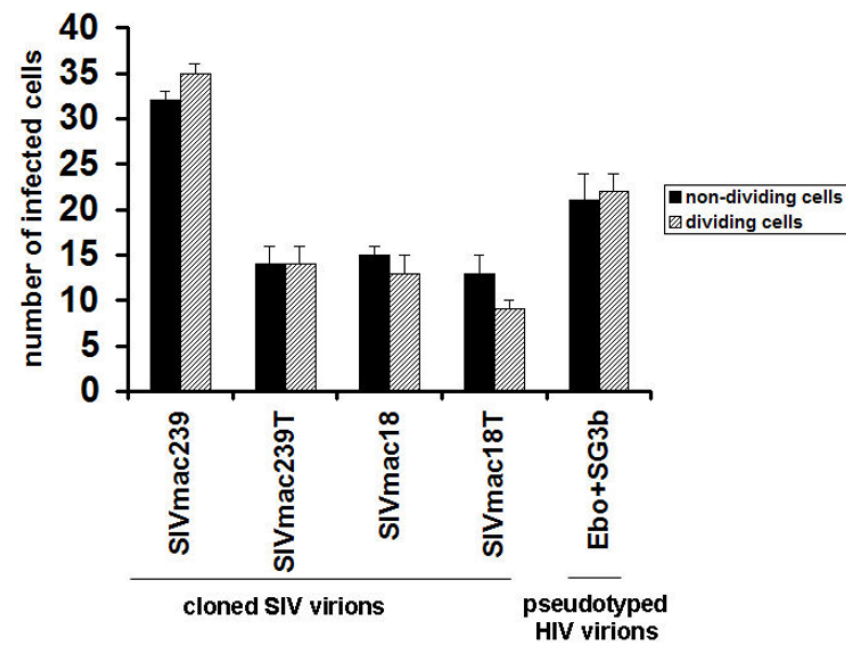

Figure 2

Infectivity of SIV with full length or truncated Env and pseudotyped HIV virions in dividing and nondividing cells. MAGI-R5 cells treated or untreated with aphidicolin were infected with SIVs or pseudotyped HIV virions. For inoculation of cells, each virus was used at a similar titer determined as described in Methods. Infectivity of SIV and HIV was measured by removal of the media after three days, fixation and staining of cells with X-gal [29]. The infectivity was determined by counting the number of infected cells in wells inoculated with viruses. Data are plotted as the mean of three experiments, each replicated twice. Error bars represent standard deviations.

SIV postentry replication events compared with truncated Env, but virus with truncated Env can overcome this restriction by high multiplicity of infection.

\section{Production of progeny SIV in dividing and non-dividing cells} To evaluate possible differences in viral particle production in dividing vs. non-dividing cells we compared the release of Gag antigen (p27) in SIV infected CEMx174 cells that were untreated or treated with aphidicolin for 24 hr before and during infection. To control for possible effects of cell viability on Gag production, a parallel MTT assay was performed. The total production of Gag was about 2-fold lower in non-dividing cells than in dividing cells infected by with full length Env SIVmac239 or with the same level in both type of cells infected by mutant SIVmac18 with full length Env (Table 2). The total production of Gag was about 2-fold higher in non-dividing cells than in dividing cells infected by SIV with truncated Env (SIVmac239T, SIVmac18T). Infection with all viruses had similar effects on viability of dividing or non-dividing (aphidicolin treated) cells; viability of cells treated with aphidicolin for 3 days was about 3-fold lower compared with cells treated for 1 day. The results indicate that release of Gag antigen into media of non-dividing cells infected

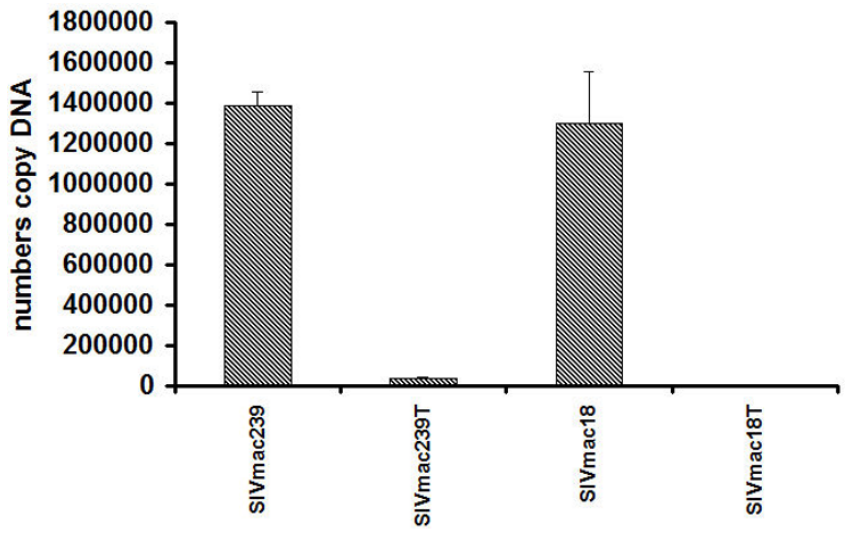

Figure 3

Comparison of early steps of replication of SIV with full length or truncated Env in rhesus monkey PBMC. Rhesus monkey PBMC $\left(3 \times 10^{6}\right)$ were inoculated by SIV with full length or truncated Env with an equal infectious index (IU/ng) using $3 \mathrm{IU} / \mathrm{ng}$ for each virus as described in Methods. Samples of nuclear DNA were tested for the presence of SIV DNA by real-time PCR in a TaqMan thermal cycler at $24 \mathrm{~h}$ after infection. Nuclear DNA samples corresponding to equal numbers of cells infected by SIV were analyzed in triplicate. Fluorescence was recorded as a function of PCR amplification cycle. Quantitative SIV determinations were made by comparison with a standard curve produced by using serial dilution of plasmid DNA.

by SIV with full length Env was restricted but there was no such inhibition for SIV with truncated Env.

In addition we compared Gag antigen production in monkey or human monocyte-derived macrophages infected with SIV full length or truncated Env. As a control, monkey M-tropic SIVmac1A11, a closely related strain to SIVmac239, with truncated Env and with other differences in sequence, important for macrophage-tropism was used [31]. Cell-free supernatants were harvested from the cultures at 7 days post-infection and tested for the presence of Gag p27 antigen. We observed release of Gag antigen from monkey macrophages infected by SIVmac1A11 but not from cells infected by SIVmac239, SIVmac239T, SIVmac18 or SIVmac18T (Table 3). A high level of Gag antigen was released into media of human macrophages infected by mutant SIVmac18T with truncated Env, a trace amount from cells infected by mutant SIVmac18 with full length Env, and release was not found in supernatant of cells infected by SIVmac239, SIVmac239T, or SIVmac1A11. The results indicate that SIV with truncated Env predominantly produced Gag antigen in macrophages.

To investigate the infectivity of particles released in the supernatant of SIV infected CEMx174 cells during 3 days 


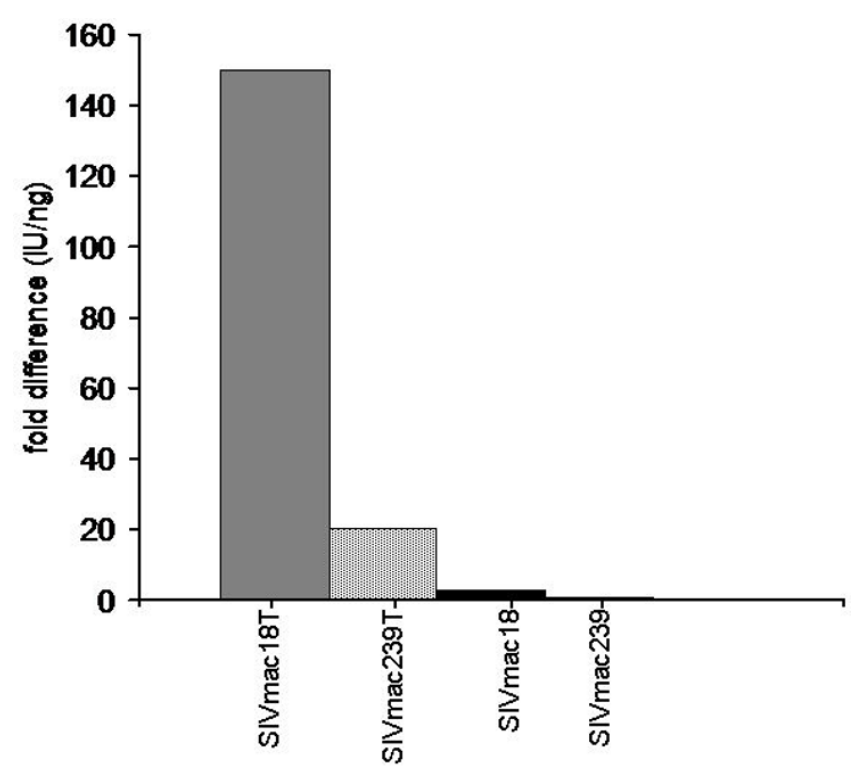

Figure 4

Analysis of efficiency of SIV replication in dividing vs non-dividing CEMxI74 cells. CEMxI74 cells $\left(2 \times 10^{6}\right)$ treated or untreated with aphidicolin were inoculated by SIV with full length or truncated Env with similar titer; the amounts of input virus was determined based on the infectious index (IU/ng) as described in Methods. At $24 \mathrm{~h}$ after infection samples of nuclear DNA were tested for the presence of SIV DNA by real-time PCR in a TaqMan thermal cycler. Nuclear DNA samples corresponding to equal numbers of cells infected by SIV were analyzed in parallel. Fluorescence was recorded as a function of PCR amplification cycle. Quantitative SIV determinations were made by comparison with a standard curve produced by using serial dilution of plasmid DNA. The ratios of replication levels in dividing:non-dividing cells are shown.

of infection from the experiment described above (Table 2), we performed a replication assay in HeLa cells expressing high levels of CCR5 and CD4 (JC-53B cells). The highest number of infectious particles was produced after 3 days post infection in all SIV infected dividing cells. We observed infectious particles in the supernatant of SIVmac239 infected dividing cells only after 3 days designated $(100 \%)$, and no infectious particles $(0 \%)$ in the supernatant of SIVmac239 infected non-dividing cells after 1 or 3 days. The absence of infectious particles was also observed with the SIVmac18 mutant that carried a full length Env. In contrast, viruses with truncated Env (SIVmac239T, SIVmac18T) produced infectious particles starting at early times post infection, 1 or 3 days post infection in dividing as well as non-dividing cells (not shown). We observed levels of about $60 \%$ infectious particles in the supernatant of SIVmac239T and about 75\% in the supernatant of SIVmac18T infected non-dividing cells after 3 days (Fig. 5). The results demonstrate that only SIV with truncated Env produced infectious particles in nondividing CEMx174 cells, although SIV with a full length Env was able to produce and release non-infectious Gag particles in these cells.

We also compared production of infectious particles containing SIVmac239, SIVmac239T, and SIVmac18T Env in $293 \mathrm{~T}$ epithelial cells. The virus stocks were prepared by transfection of 293T cells with similar amounts of DNA. The level of extracellular Gag in cells infected by SIVmac239 was about 3-fold higher than in cells infected by SIV239T or SIVmac18, and about 5-fold higher than in cells infected by SIVmac18T (Table 4). The infectivity titer in supernatants from transfected cells was analyzed using indicator cell lines. We found that the infectivity titer of SIV with truncated Env was about 6 to 30 -fold higher than SIV with full length Env. SIV with a full length Env apparently produces reduced levels of infectious particles in human $293 \mathrm{~T}$ cells, although total particle release was higher than in cells infected by SIV with truncated Env. Taken together, the results indicated that production of particles by SIV with full length Env was cell type dependent: particles were produced in monkey PBMC and release of particles was inhibited in human T cells and macrophages. In contrast, SIV with truncated Env produced infectious particles in all types of cells tested.

\section{Effects of modifications in the long cytoplasmic tail on lipid raft association and assembly of SIV in $293 \mathrm{~T}$ cells}

The SIV Env glycoprotein with a long but not with a truncated CT is palmitoylated at a single cysteine at residue position 787, which may be important for its interactions with cellular proteins. However, mutations that change

Table 2: Production of Gag antigen SIV in dividing and non-dividing CEMxI74 cells.

\begin{tabular}{ccccc}
\hline Virus & MTTI +aphid I day/+aphid 3 days (OD) & Viability index (fold difference) & $p 27 \mathrm{ng} / \mathrm{m}^{2}$-aphid.3 days & $p 27 \mathrm{ng} / \mathrm{m} \mathbf{R}^{2}+a p h i d .3$ days $(\times 3)^{3}$ \\
\hline SIVmac239 & $0.327 / 0.106$ & 3 & 28 & 17 \\
SIVmac239T & $0.302 / 0.105$ & 2.9 & 32 & 41 \\
SIVmac18 & $0.334 / 0.104$ & 3.2 & 10 & 12 \\
SIVmac18T & $0.386 / 0.117$ & 3.7 & 19 & 41 \\
\hline
\end{tabular}

IMTT assay is described in Methods

${ }^{2}$ Amount of Gag P27 antigen in supernatants determined by ELISA described in Methods

3 amount was adjusted in according to results of MTT assay. 
Table 3: Production of Gag antigen SIV in macrophages.

\begin{tabular}{ccc}
\hline Virus & Macaque macrophages $\mathrm{p} 27 \mathrm{ng} / \mathrm{ml}$ & Human macrophages $\mathrm{p} 27 \mathrm{ng} / \mathrm{ml}$ \\
\hline SIV239 & 0 & 0 \\
SIV239T & 0 & 0 \\
SIVI8 & 0 & 2 \\
SIVI8T & 0 & 40 \\
SIVIAII & 15 & 0 \\
\hline
\end{tabular}

'Amount of Gag p27 antigen in supernatants (24-well plate) determined by ELISA described in Methods.

the full length Env glycoprotein palmitoylation state did not alter its transport, surface expression or cell fusion activity [32]. Since palmitoylation could be involved in lipid raft association, the association of the Env glycoprotein with detergent resistant microdomains was compared for SIVmac239 with a long cytoplasmic tail (SIVmac239Env), the Env mutant with a truncated TM glycoprotein (SIVmac239-EnvT) and a palmitoylation site mutant in which the cysteine at position 787 was changed to serine

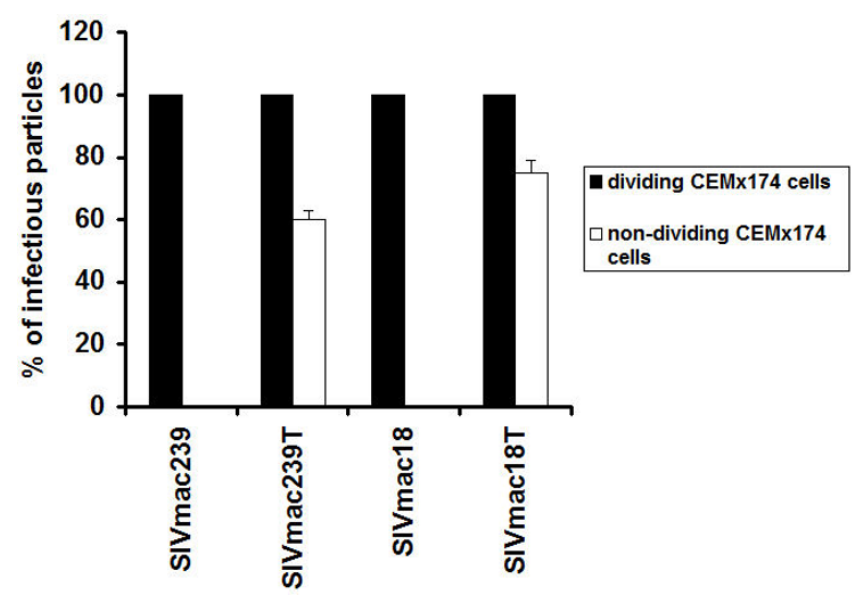

Figure 5

Production of SIV infectious particles in dividing and non-dividing CEMxI74 cells. CEMxI74 cells in a 96-well plate about $3 \times 10^{4}$ per well treated or untreated with aphidicolin were infected by SIV variants with the same titer determined as described in Methods. The supernatants were collected after $I$ and 3 days post infection and the p27 content was determined by ELISA Core Antigen assay (Table 2). SIV particles with about $0.5 \mathrm{ng} /$ well of p 27 antigen were used for inoculation of JC-53B cells. The infectivity of particles was measured by removal of the media after 3 days, fixation and staining of cells with $X$-gal. The percent of particle infectivity was determined by dividing the number of infected cells in wells inoculated with particles collected from supernatants of SIV infected non-dividing cells by the number in wells inoculated with particles collected from supernatants of SIV infected dividing cells after 3 days (the maximum amount for each virus). Data are plotted as the mean of three experiments, each replicated twice.
(SIVmac239-EnvC787S). These glycoproteins were found to be expressed and efficiently processed in human CEMx174 cells at similar levels (not shown). However, differences were observed in targeting of these viral envelope glycoproteins to detergent-resistant membrane microdomains (Fig. 6). The full-length wild-type as well as the palmitoylation-deficient mutant SIVmac239Env C787S glycoproteins were both found in the low-density sucrose gradient fraction, while the Env glycoprotein with a truncated cytoplasmic tail was not apparently targeted to lipid rafts, since it was not found in the low-density fractions. These results indicate that the long cytoplasmic tail of the Env glycoprotein but not its palmitoylation is required for incorporation of Env into lipid rafts. The SIV viruses with truncated Env glycoproteins are therefore able to replicate efficiently in cell lines despite their lack of Env lipid raft association.

To compare the assembly of different Env glycoproteins into virions, we transfected human $293 \mathrm{~T}$ cells with equal amounts of proviral DNA. At 3 days post transfection cells and supernatants were collected and analyzed by RT assay (not shown). We found similar levels of RT activity in supernatants from cells infected by SIV with full length or truncated Env glycoproteins. The lowest RT activity, about 100-fold lower than in other SIV samples, was observed in supernatants from cells infected by SIV with the C787S Env mutant which eliminated palmitoylation. The infectivity titer of SIV with truncated Env was about 6 to 30fold higher than SIV with full length Env as described above (Table 4). These results indicate that palmitoylation enhances virus replication and/or assembly viruses with full length Env but is not required in viruses with truncated Env.

\section{Effects of full length and truncated Env on host-cell gene expression}

We also analysed the effect of Env glycoprotein differences on cellular transcriptional responses to infection. PBMC cells were infected with SIVmac239 variants with full length or truncated Env glycoproteins. Both viruses infected about $30 \%$ of cells at 6 days post infection as detected by flow cytometry. We examined mRNAs from 
Table 4: Replication of SIV variants generated in human 293T cells.

\begin{tabular}{ccccc}
\hline Virus $^{a}$ & $J C-53 B$ titerb $I U c / m l$ & ELISA $(p 27)^{b} \mathrm{ng} / \mathrm{ml}$ & IU/ng & (fold difference from SIVmac239) \\
\hline SIVmac239 & $1 \times 10^{3}$ & 306 & 3 & - \\
SIVmac239T & $6 \times 10^{3}$ & 101 & 59 & 20 \\
SIVmac18 & $1 \times 10^{3}$ & 117 & 9 & 3 \\
SIVmac18T & $3 \times 10^{4}$ & 65 & 461 & 154 \\
\hline
\end{tabular}

aViruses were obtained simultaneously after transfection of 293T cells with equimolar amounts of DNA.

bAssays are described in Methods.

Infectious units

SIVmac239 and SIVmac239T infected cells, and compared transcriptional responses to those observed in uninfected PBMC. The results were verified by real-time PCR with the same RNA samples (Table 5). The real-time PCR data confirmed that SIV with full or truncated Env induced similar cellular transcriptional responses. No changes were observed in levels of mRNA induction by SIV with full and truncated Env. These results show that the differences in the Env cytoplasmic tail did not result in major differences in effects on host-cell transcriptional responses.

\section{Discussion}

The differences in properties between SIV with full length or truncated Env have been previously studied with respect to pathogenicity [17], fusion activity $[10,11]$, and assembly $[4,9,25]$. In the present study we had several goals: to study the possible role of the long cytoplasmic tail of the Env glycoprotein in post-entry events, to examine the lipid raft association of Env glycoproteins with full length or truncated cytoplasmic tails, and to compare

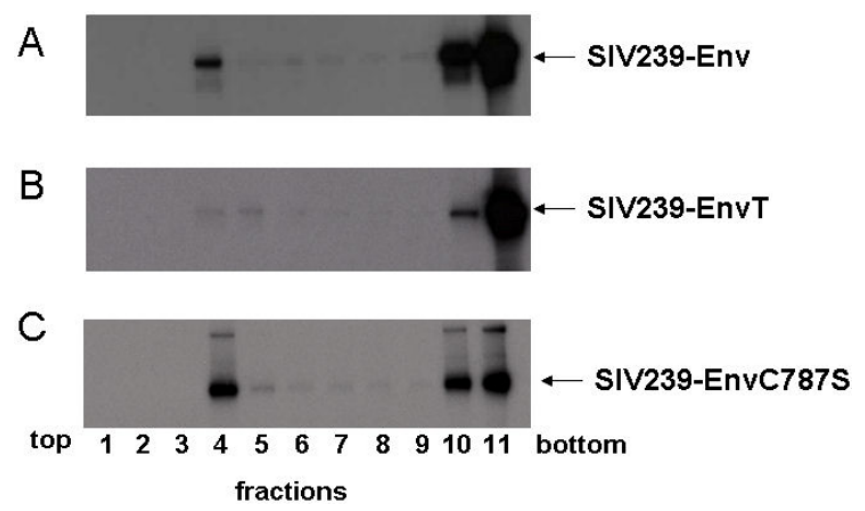

\section{Figure 6}

Lipid raft association of the SIV Env protein. The interaction of the Env protein of SIVmac239 (A), SIVmac239-EnvT (B), and SIVmac239-EnvC787S (C) with lipid rafts was analyzed in a discontinuous sucrose gradient. CEMxI74 (A, B, C) cells were infected with 2 pfu/cell of respective vaccinia recombinant viruses. The infected cells were labeled with ${ }^{35} \mathrm{~S}$-methionine/cysteine, disrupted by detergent TX-100 and a discontinuous sucrose gradient of 5 to $30 \%$ sucrose was used to obtain II fractions as described in Methods. assembly and release of SIV with full length and truncated Env in dividing and non-dividing cells. We also compared several cloned SIV viruses with sequence differences in the SU and CT subunits of the Env glycoprotein, that were related to adaptation to HUT78 cells [25].

The early steps of HIV and SIV infection include the attachment of viruses to host cells, entry and transport of the genome to the transcription site, formation of the PIC, and import to the nucleus. Electron microscopic studies showed that HIV cores were disrupted shortly after viruscell fusion [33] and viral RNA and associated proteins were released into the cytoplasm and were likely to interact with the cytoskeleton [28]. We found that early steps in replication of SIV with full length or truncated Env were similar in dividing and non-dividing cells. Our results also indicated that internalization of SIV was correlated with amount of p24 input, but not with differences in Env glycoproteins (not shown). Previous studies also indicated that viruses might be internalized into cells irrespectively of CD4 surface expression and with almost equal efficiencies in cells susceptible or not susceptible to HIV infection [34]. The most striking differences were observed when we compared post-entry relocation of SIV with full length or truncated Env using similar input virus levels. The proviral DNA of SIVmac239 with full length Env was transported to the nucleus about 20-fold more efficiently than SIVmac239T with truncated Env, and 100-fold more efficiently than the SIVmac18T variant with a truncated cytoplasmic tail and with a single mutation A239T in the SU subunit. In contrast, the proviral DNA of SIVmac18 with a full length Env and with a single mutation A239T in the SU subunit was transported to nucleus almost as efficiently as the parental SIVmac239. Env glycoproteins are not involved in nuclear import of the HIV pre-integration complex [35], which may suggest that the effects of Env glycoproteins during early steps of SIV infection is associated with other steps in post-entry replication.

We observed release of infectious SIV particles with full length Env in monkey PBMC cells, but a restriction of particle release in human CEMx174, HUT78, epithelial 293T, or in macrophages. These results are consistent with previous studies indicating that replication of T-tropic SIV 
and HIV with full length Env is inhibited at a post-nuclear step in macrophages [36,37]. Our results also demonstrated that a mutation in the long cytoplasmic tail that eliminates palmitoylation did not abolish Env incorporation into lipid rafts as was described for HIV-1 [38], but prevented virus assembly. In contrast to HIV-1 [39] our results indicate that palmitoylation of the SIV Env cytoplasmic tail is not a prerequisite association with detergent insoluble microdomains. Similar results have been reported for EBV; the interaction of LMP-1 with lipid rafts was shown to be independent of palmitoylation [40]. Furthermore, palmitoylation of viral transmembrane proteins does not necessarily trigger interaction with lipid rafts, since palmitoylated VSV G protein is found in a TX100 soluble membrane fraction [41]. Palmitoylation was critical for infectivity of SIV with full length Env, and also may impact HIV-1 infectivity $[39,42]$. Inhibitory factors such as TRIM $5 \alpha$ target the CA and/p2 components of the incoming virus and presumably would be able to restrict infection of both viruses with full length and truncated Env $[43,44]$.

In contrast to SIV with full length Env, similar levels of assembly and release were observed for SIV with truncated Env in monkey PBMC, human HUT78, CEMx174, 293T, growth-arrested CEMx174 cells and macrophages resulting in production of infectious particles. We previously observed that SIVmac239T Env with a truncated cytoplasmic tail exhibited the ability to self-associate on the cell surface and assemble into a more closely packed array than full-length Env [9]. Our results indicated that the long cytoplasmic tail of the Env glycoprotein is required for incorporation of Env into lipid rafts, but Env truncation allows SIV to replicate under conditions that are nonpermissive for SIV with the full length Env glycoprotein. Since SIV viruses with truncated Env glycoproteins are able to establish productive infection, lipid raft association is apparently not required for virus replication and truncated Env is assembled into infectious SIV virions even though it was not incorporated into lipid rafts. Truncation of the cytoplasmic domain of the SIV Env glycoprotein alters the conformation of the external domain and results in more stable oligomers of TM glycoprotein [45], and the truncated Env glycoprotein is more fusogenic than the full length Env $[10,11]$. These features for incoming virus particles may result in less dependence on the lipid composition of the viral membrane. However, a recent study reported that cholesterol-depleted HIV-1 virions exhibited a defect in internalization [46]. Taken together, the results suggest that SIV with a truncated cytoplasmic tail can overcome a restriction in post-nuclear replication events, but exhibits a defect in early replication events in human and monkey cells.
Circulation of SIV with truncated Env among disease resistant primates in Africa or disease sensitive primates in Asia may indicate that this form of virus appeared when virus is adapting to new cells such as such as epithelial on brain cells, macrophages [47] or in response to factors controlling pathogenicity of virus [43]. However, experimental infection of monkeys by SIV with truncated Env showed a restricted circulation of this virus in PBMC $[15,48]$. Our results suggest that the restricted circulation of Env-truncated variants in vivo may be related to a defect in a post-entry step (Fig. 7A). The virus with full length Env has higher specific infectivity than virus with truncated Env, and is capable to establish productive infection in permissive $\mathrm{T}$ cells and persistent infection in non-permissive cells such as epithelial and dendritic cells or macrophages $[49,50]$ because early steps in replication appear to be more efficient in viruses having a long cytoplasmic tail incorporated into lipid rafts domains of incoming particles (Fig. 7A, B). However, SIV with truncated Env can overcome this early restriction by high multiplicity of infection (Fig. 7B). A high multiplicity of infection would be difficult to obtain by virus with truncated Env in vivo, because of its sensitivity to the humoral immune response [47]. This is a possible reason why a most viruses with truncated Env were derived from tissues of immunocompromised macaques, or from brain tissue, an immuneprivileged site. We suggest that the long cytoplasmic tail of the Env glycoprotein may interact with viral (p17) [1] or cellular proteins [32]. It was shown that the HIV-1 envelope glycoprotein with a long cytoplasmic tail directly influences the site of release of Gag particles in polarized epithelial cells [5] and microtubules may play an important role in assembly and maintenance of the polarized viral budding platform. Treatment of infected T cells with inhibitors of actin or tubulin remodeling disrupted Gag and Env compartmentalization within the polarized raftlike domains [51]. Co-localization of the reverse transcription complex with actin microfilaments and viral matrix was also observed during early steps in replication $[28,52]$. We suggest that the long cytoplasmic tail of the Env glycoprotein may affect interaction of viral core proteins with the cytoskeleton, which is important for viral relocation to the transcriptional site. Finally, our results may help to develop a strategy against pathogenic forms of HIV which could prevent the initial infection process. One example is development of topical microbicides targeted to post entry inhibition of HIV infection by interfering with Env function in an early step of virus replication [53].

\section{Conclusion}

The present results indicate that a possible basis for defective replication of SIV with truncated Env in primates may be a restriction during an early step of replication, whereas defective replication of SIV with full length Env in human 
A
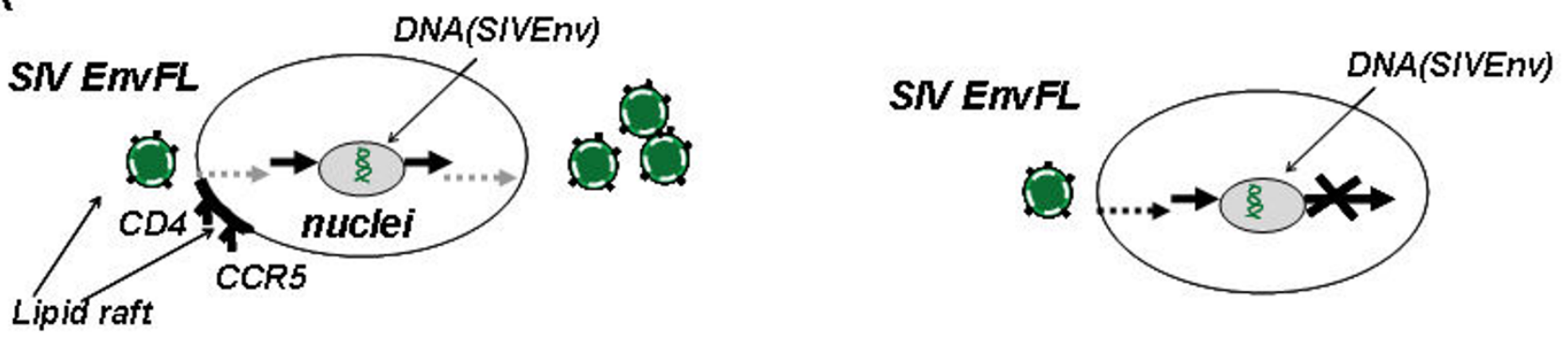

B
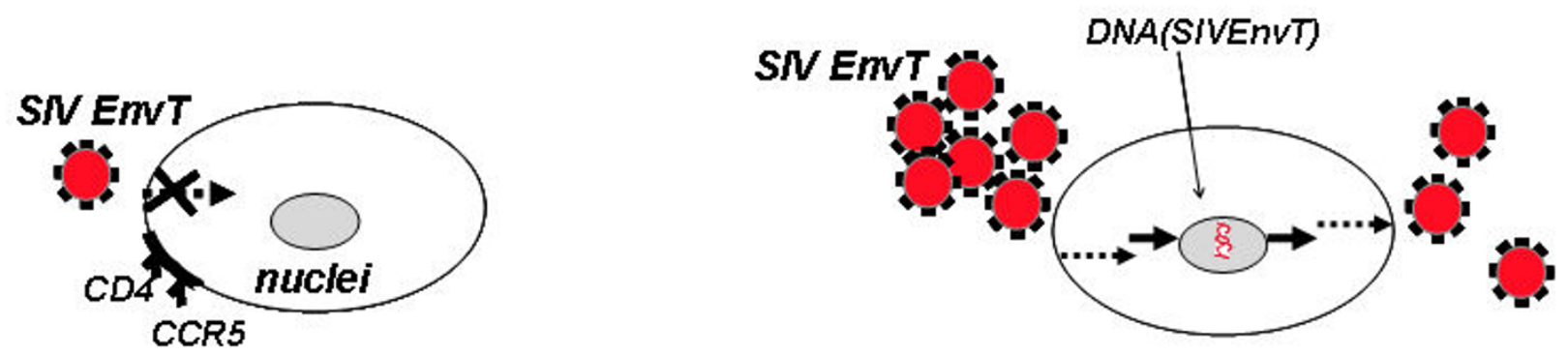

Figure 7

Schematic comparison of SIV with full length and truncated Env. Replication of SIV with full length Env (A) or with truncated Env (B) in permissive (monkey PBMC) cells (left diagrams) and non-permissive cells (brain cells, macrophages) (right diagrams). Schematic depiction of the trafficking of SIV in cells: Gray dashed arrows depicted raft-associated pathway; black dashed arrow depicts alternative pathway; black arrows depicted sites of transcription. SIV with truncated Env can overcome a restriction in an early replication step by high multiplicity of infection and productively infect cells.

T cells may result from a restriction during a late step of replication and assembly. Comparable host-cell transcriptional responses in rhesus monkey PBMC to both types of virus infection also indicates that cells respond similarly to replication of SIV with full length or truncated Env. A mutation in the Env sequence relating to T cell adaptation alters SIV properties including sensitivity to neutralization, level of Env incorporation, rate of replication and association with lipid rafts during the course of adaptation to human cells.

\section{Methods}

\section{Cell and virus stocks}

The recombinant monkey cell lines sMAGI and human MAGI-R5 were obtained from the NIH AIDS Research and Reference Reagent Program. T-cell line HUT78 and T-B hybrid cell line CEMx174 were obtained from the American Type Culture Collection (Manassas, VA). The recombinant epithelial human cell line JC53-BL (indicator cell line), which is a derivative of HeLa cells that expresses high levels of CD4 and coreceptors CCR5 and CXCR4 [54], was obtained from Dr. J. Kappes (University of Alabama, Birmingham). The human 239T cell line was kindly provided by Dr. S. L. Lydy. Rhesus monkey PBMCs were separated by centrifugation of whole blood over LSM Lymphocyte Separation Medium (ICN Biomedicals Inc., Costa Mesa, CA). Cells were then stimulated with concanavalin A (Con A, $5 \mu \mathrm{g} / \mathrm{ml}$ in RPMI 1640 containing 10\% heat-inactivated fetal calf serum; interleukin-2, human (hIL-2), $10 \mathrm{U} / \mathrm{ml} ; 10 \mathrm{mM}$ HEPES; and antibiotics) for three days before virus infection. To prepare monkey macrophages, PBMC were isolated as described above. Cells ( $3 \times 10^{7}$ in RPMI 1640 containing $15 \%$ human $\mathrm{AB}^{+}$serum, $1.5 \mathrm{ng} / \mathrm{ml}$ of M-CSF, and $0.08 \mathrm{ng} / \mathrm{ml}$ of GM-CSF) were seeded into $100-\mathrm{mm}$ plates or split into 24 -well plate and incubated for 4 days to allow adherence of monocytes. After removal of nonadherent cells, cells were incubated for another 3-4 days before infection.

SMAGI, MAGI-R5, JC53-BL, and 239T cells were maintained in Dulbecco's minimal essential medium (DMEM) supplemented with $10 \%$ fetal calf serum and antibiotics. HUT78 and CEMx174 cells were maintained in RPMI 1640 supplemented with $10 \%$ fetal calf serum and antibiotics, and buffered by $10 \mathrm{mM}$ HEPES.

Preparation of cloned SIV stocks, standardization of virus titers, and conditions for virus infection were done as 
Table 5: Comparison of mRNA responses by real-time PCR'.

\begin{tabular}{cc}
\hline Genes & SIVmac239T/SIVmac239 (fold difference) \\
\hline IL2 & 1.34 \\
IL4 & 1.76 \\
IL6 & -1.32 \\
IL7 & -1.41 \\
ILI0 & -1.05 \\
ILI2p40 & 1.09 \\
ILI5 & -1.16 \\
IFNAI & 1.13 \\
IFN $\alpha$ & 1.15 \\
IFN $\beta$ & 1.04 \\
IFN $\gamma$ & -1.14 \\
Mx & -2.22 \\
TNFa & -1.11 \\
IRFI & 1.09 \\
IRF2 & 1.05 \\
IRF3 & -1.09 \\
IRF4 & 1.09 \\
IRF5 & 1.13 \\
IRF7 & -1.27 \\
PU.I & 1.06 \\
SPIB & -1.05
\end{tabular}

IRNA samples were the same as used for microarray assay. ${ }^{2}$ Changes in cellular mRNA levels after infection by SIV with full length Env were compared with mRNA levels in cells infected by SIV with truncated Env and expressed in folds.

Note fold repression is indicated by a minus sign

described earlier [25]. It is commonly accepted to use the infectious titer [55] or TCID50 [56] for measurement of the quantity of SIV and HIV. However, these methods are not able to precisely compare viruses with different properties such as rate of replication or production of noninfectious particles. We used infectious the index (IU/ng) which is the ratio between infectious titer and core antigen, which is taking both of these characteristics into consideration.

Prior to cell infection, virus preparations were treated with $200 \mathrm{U} / \mathrm{ml}$ RNase-free DNase I in growth medium containing $10 \mathrm{mM} \mathrm{MgCl}_{2}$ for $30 \mathrm{~min} 37^{\circ} \mathrm{C}$ to remove contaminating proviral DNA [57]. Plasmid pHIVSG3 containing the HIV-1 provirus (SG3) with a deleted env gene was a generous gift from Beatrice Hahn. Plasmid pCMV-GP encoding the Ebola envelope protein GP was provided by C. Yang. The plasmid pRB239ser-787 which carried a mutation in the long cytoplasmic tail of the Env glycoprotein of SIVmac239 C787S to eliminate palmitylation (see below) was digested by NheI and BglII and the resulting fragment with the mutation was introduced in plasmid p3'239 which contained the 3' portion of molecularly cloned SIVmac239 [25] in identical restriction sites. The plasmid, designated p3'239ser-787, was used to obtain a mutant virus as described above.

\section{Construction of recombinant vaccinia viruses}

Recombinant vaccinia viruses expressing the SIVmac239Env or SIVmac239-EnvT were described previously [9]. For the construction of SIVmac239-EnvC787S the codon TGC (cysteine) was changed to AGT (serine) by overlapping PCR. The env gene was amplified from p239SpE3' (NIH AIDS Research and Reference Reagent Program) by using the following primers: primer A (with EcoRI restriction site), CAAAGAATTCAGTATGGGATG; primer B (overlapping primer), GGTTTCTACTGTTGCTGA; primer $\mathrm{C}$ (overlapping primer), TCAGCAACAGTAGAACC; and primer D (with restriction site of StuI), GTATTTCTAGGCCTCACAAGAG. Primers B and C carried the codon to be changed. Two PCR amplifications were carried out by using the p239SpE3' plasmid as template. Each PCR was carried out for 25 cycles with steps of $1 \mathrm{~min}$ at $95^{\circ} \mathrm{C}, 2$ $\min$ at $50^{\circ} \mathrm{C}$, and $3 \mathrm{~min} 72^{\circ} \mathrm{C}$. The PCR products were purified with a gel extraction kit (Qiagen) according to the manufacturer's protocol. The two overlapping PCR fragments $A B$ and $C D$ were joined by mixing and a PCR reaction with the external primers A and D was performed. The resulting PCR fragment AD was initially cloned in the pDrive vector (Qiagen). The plasmid was digested with EcoRI and StuI and the fragment was cloned in vector pRB21. The resulting plasmid was designated pRB239ser787 and used for preparation of recombinant vaccinia virus as described [58].

\section{SIV infection}

Conditions for infection with SIV were described previously [25]. At $24 \mathrm{~h}$ before infection, $3 \times 10^{6}$ cells were treated with $5 \mu \mathrm{g} / \mathrm{ml}$ aphidicolin, and cells were inoculated with SIV for $2 \mathrm{~h}$ in medium with $15 \mathrm{ug} / \mathrm{ml}$ DEAEdextran with or without aphidicolin.

After this incubation unbound virus was removed by three washes and medium with or without aphidicolin was added. For 3 day samples, new medium with $5 \mu \mathrm{M}$ AZT and with or without aphidicolin was added after 1 day. After 1 and 3 days, the culture supernatant and cells were harvested from each well and used for assays. The p27 content was determined by ELISA Core Antigen assay (Coulter Corporation). The infectivity of virus particles was determined by $\beta$-galactosidase assays in JC53-BL [54], MAGI-R5 or SMAGI cells [29,59].

\section{Supernatants, cell and nuclear extracts}

The supernatants were harvested and clarified by centrifugation at $3.5 \mathrm{k}$ for $20 \mathrm{~min}$ (GS-15R, Beckman). Cells were washed three times with PBS and lysed in RIP buffer [9] and production of Gag antigen was analyzed by SIV Core Antigen Assay (Coulter Corporation). The culture supernatants were also assayed for RT activity by colorimetric reverse transcriptase assay (Roche). 
To prepare cell extracts, the cells $\left(3 \times 10^{6}\right)$ were suspended in $0.01 \mathrm{M} \mathrm{NaCl}, 0.01 \mathrm{M} \mathrm{MgCl}_{2}$ [pH 7.4] for 10 min on ice and then lysed by addition of NP-40 to $1 \%$ followed by vortexing as described previously by [36]. Nuclei were recovered by centrifugation at $12,000 \times \mathrm{g}$ for $2 \mathrm{~min}$, and nuclear DNA was extracted with a Dneasy Tissue kit (Qiagen) and analyzed by RT-PCR.

\section{RNA preparation and microarray analysis}

Total RNA was extracted from cells by using the Rneasy kit (Qiagen, Valencia, CA), according to the manufacturer's protocol. Reverse transcription, second-strand synthesis, and probe generation were accomplished by standard Affymetrix protocols. The Gene Chip HG_U133_Plus 2.0 array (Affymetrix), containing $\approx 33,000$ known genes, was hybridized, washed, and scanned according to Affymetrix protocols within the Baylor Affymetrix Core facility. Changes in cellular mRNA levels after SIV infection were compared with mRNA levels in controls that were identically plated, treated, and incubated in the absence of virus. GeneSpring, version 6.2 was used to normalize and scale results and compare viral responses to those of controls. The program clusters increases or decreases of expression levels as the fold change relative to control.

\section{Real-time PCR amplification for SIV}

Quantification of proviral DNA from infected cells was performed by real-time PCR using the TaqMan amplification system as described elsewhere [37]. For PCR amplification for the SIV gag region, forward and reverse PCR primers were SIVgagF AGTACGGCTGAGTGAAGGCAGTA and SIVgagR GACCCGCGCCTTTATAGGA, respectively. The fluorogenic SIVgag probe CGGCAGGAACCAACCACGACG was modified with FAM/TAMRA [37]. PCR amplification for the SIV 2LTR region was carried out. Forward and reverse PCR primers were U3U5-2LTRF GGAACGCCCACTTTCTTGATGTATA and U3U5-2LTRR CGGCGGCTAGGAGAGATG. The fluorogenic 2LTR probe was SIV U3U5-2LTRM2 FAM AACACACACTAGCTAATACAG. Nuclear DNA samples corresponding to equal numbers of cells infected by SIV were analyzed in parallel. Fluorescence was recorded as a function of PCR amplification cycle. Quantitative SIV determinations were made by comparison with a standard curve produced by using serial dilution of plasmid DNA with a $1890 \mathrm{bp}$ region of the SIVmac239 gag gene [60].

\section{RNA isolation and CDNA synthesis}

To determine the mRNA transcription profile of selected genes the relative quantitative real-time PCR was performed. PBMC were harvested from cell culture and lysed immediately with $350 \mu \mathrm{l}$ of lysis buffer from the MagNA Pure LC RNA Isolation Kit III (Tissue) (Roche), then frozen at $-80^{\circ} \mathrm{C}$. Collected samples were extracted with a MagNa Pure LC - robotic workstation (Roche Molecular
Biochemicals) with the same kit using the external lysis protocol. Total RNA was eluted in $60 \mu \mathrm{l}$ of water and optical density measurements were taken immediately. All total RNA was reverse-transcribed using a High-Capacity cDNA Archive Kit Protocol (Applied Biosystems Inc.).

\section{Quantitative Real-Time PCR Analysis}

The reaction was carried out on a 384-well optical plate (Applied Biosystems) in a $20-\mu$ l reaction volume containing $30 \mathrm{ng}$ of cDNA per reaction with TaqMan Universal PCR Mastermix, Applied Biosystems. All sequences were amplified using the Applied Biosystems 7900HT Sequence Detection System with the PCR profile: $50^{\circ}$ for $2 \mathrm{~min}, 95^{\circ} \mathrm{C}$ for $10 \mathrm{~min}$, followed by 45 cycles at $95^{\circ} \mathrm{C}$ for $15 \mathrm{~s}$, and $60^{\circ} \mathrm{C}$ for $1 \mathrm{~min}$. Samples were tested in duplicate, in parallel with the housekeeping gene GUSB. For relative quantitation delta-delta $\mathrm{Ct}$ analysis was applied to recalculate the fold differences between samples.

\section{Primer and probe sequences}

Oligonucleotide primers and probes for IL-2, IL-4, IL-6, TNF- $\alpha$, IFN- $\alpha$, TNF- $\beta$, and Mx were used as described by [61]. For IL-10 were used two sets of primers and probes. For IL-10 assay a first set of oligonucleotide primers and probe were used as described by [62] and a second set described below. For other assays oligonucleotide primers and probes were designed using the Primer Express Software (Applied Biosystems) based on published rhesus macaque sequences.

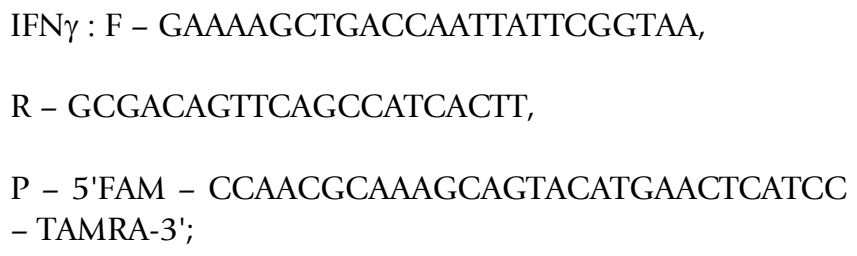




\section{IL-15 F - AGCTGGCATTCATGTCTTCATTT,}

R - CACCCAGTTGGCTTCTGTTTTAG,

P - 6FAM - CTGTTTCAGTGCAGGGC - MGBNFQ.

Primers and probes were obtained from Applied Biosystems with assay ID as follows: SPIB - Hs00162150_m1; PU.1 - Hs00231368_m1; IRF1 - Hs00971959_m1; IRF2 - Hs00180006_m1; IRF3 - Hs00155574_m1; IRF4 Hs00277069_m1; IRF5 - Hs00158114_m1; IRF7 Hs00185375_m1; IFNA1 - Hs00256882_s1. All these assays were designed based on human sequences, and before implementation all assays were validated for rhesus macaques.

\section{Isolation of lipid raft proteins}

Radioactively labeled cells expressing different recombinant Env glycoproteins were washed three times with ice cold PBS+++ and then lysed on ice in $750 \mu \mathrm{l}$ TNE buffer (10 mM Tris $\mathrm{HCl} \mathrm{pH} \mathrm{7.5,150} \mathrm{mM} \mathrm{NaCl,} 5 \mathrm{mM}$ EDTA with a protease inhibitor cocktail (Roche)) with $0.5 \%(\mathrm{v} / \mathrm{v}) \mathrm{TX}-100$ for $20 \mathrm{~min}$ as described previously [63]. The lysate was passed 10 times through a $25 \mathrm{G}$ needle on ice and subsequently centrifuged at $8000 \times \mathrm{g}$ for 10 $\min$ at $4{ }^{\circ} \mathrm{C}$. The supernatant was brought to $40 \%$ sucrose by adding $750 \mu \mathrm{l}$ of $80 \%(\mathrm{w} / \mathrm{v})$ sucrose in TNE, loaded into the bottom of a SW41 centrifuge tube and overlaid with $6 \mathrm{ml}$ of $30 \%(\mathrm{w} / \mathrm{v})$ sucrose in TNE and $3.5 \mathrm{ml} 5 \%(\mathrm{w} /$ v) sucrose in TNE. The samples were spun to equilibrium at $200,000 \times \mathrm{g}$ for $13-16 \mathrm{hr}$. Eleven fractions with volume of each $1 \mathrm{ml}$ were collected started from the top of the gradient and subjected to immunoprecipitation with monkey anti-SIV serum. Samples were analyzed with an SDS$8 \%$ PAGE gel and subsequent autoradiography.

\section{MTT assay}

For the MTT assay, aphidicolin treated or untreated CEMx174 cells in 96-well plates were infected with SIV. After $24 \mathrm{~h}$ or $72 \mathrm{~h}$ incubation, $10 \mu \mathrm{l}$ of MTT $(10 \mathrm{mg} / \mathrm{ml})$ reagent was added to $100 \mu \mathrm{l}$ of medium in each well. After $4 \mathrm{~h}$ incubation at $37^{\circ} \mathrm{C}, 100 \mu \mathrm{l}$ acidic isopropanol $(0.04$ $\mathrm{M} \mathrm{HCl}$ in absolute isopropanol) was added. The absorbance was read in a computer-controlled photometer. The absorbance at $690 \mathrm{~nm}$ was automatically subtracted from the absorbance at $540 \mathrm{~nm}$ to eliminate the effects of nonspecific absorption. The MTT assay, which provides an indication of mitochondrial integrity and activity, is not dependent on the cell cycle.

\section{Competing interests}

The author(s) declare that they have no competing interests.

\section{Authors' contributions}

Author ANV designed experiments, carried out most the experiments and wrote the manuscript. Author AW carried out most experiments for the lipid raft section and drafted this section. NLK assisted in RT-PCR experiments. VK and BY carried out microarray analysis. RWC suggested experiments and revised the manuscript.

\section{Acknowledgements}

This study was supported by NIH grants Al028I47 and Al45883 from the National Institute of Allergy and Infectious Diseases and Emory CFAR grant (P30 Al050409) for using real-time PCR instruments. A.W. was supported by a fellowship from the Bundesministerium für Bildung und Forschung, Germany (BMBF-LPD 990I/8-29).

The authors thank Dahnide Taylor for technical assistance and Erin-Joi Collins for assistance in preparing the manuscript.

\section{References}

I. Yu X, Yuan X, Matsuda Z, Lee TH, Essex M: The matrix protein of human immunodeficiency virus type $I$ is required for incorporation of viral envelope protein into mature virions. J Virol 1992, 66:4966-497|.

2. Cannon PM, Matthews S, Clark N, Byles ED, lourin O, Hockley DJ, Kingsman SM, Kingsman AJ: Structure-function studies of the human immunodeficiency virus type I matrix protein, pI 7. J Virol 1997, 71 :3474-3483

3. Freed EO, Martin MA: Domains of the human immunodeficiency virus type I matrix and gp4 I cytoplasmic tail required for envelope incorporation into virions. J Virol 1996, 70:34I-35I.

4. Vincent MJ, Melsen LR, Martin AS, Compans RW: Intracellular interaction of simian immunodeficiency virus Gag and Env proteins. J Virol 1999, 73:8|38-8I44.

5. Owens RJ, Dubay JW, Hunter E, Compans RW: Human immunodeficiency virus envelope protein determines the site of virus release in polarized epithelial cells. Proc Natl Acad Sci USA I991, 88:3987-3991.

6. Lodge R, Gottlinger H, Gabuzda D, Cohen EA, Lemay G: The intracytoplasmic domain of gp4I mediates polarized budding of human immunodeficiency virus type I in MDCK cells. J Virol 1994, 68:4857-486I.

7. Zingler K, Littman DR: Truncation of the cytoplasmic domain of the SIV envelope glycoprotein increases Env incorporation into particles and fusogenicity and infectivity. J Virol 1993, 67:2824-283I.

8. Johnston PB, Dubay JW, Hunter E: Truncations of the simian immunodeficiency virus transmembrane protein confer expanded virus host range by removing a block to virus entry into cells. J Virol 1993, 67:3077-3086.

9. Vzorov AN, Compans RW: Assembly and release of SIV env proteins with full-length or truncated cytoplasmic domains. Virology 1996, 221:22-33.

10. Ritter GD, Mulligan MJ, Lydy SL, Compans RW: Cell fusion activity of the simian immunodeficiency virus envelope protein is modulated by the intracytoplasmic domain. Virology 1993, 197:255-264.

II. Spies CP, Compans RW: Effects of cytoplasmic domain length on cell surface expression and syncytium- forming capacity of the simian immunodeficiency virus envelope glycoprotein. Virology 1994, 203:8-19.

12. Broussard SR, Staprans SI, White R, Whitehead EM, Feinberg MB, Allan JS: Simian immunodeficiency virus replicates to high levels in naturally infected African green monkeys without inducing immunologic or neurologic disease. I Virol 200I, 75:2262-2275.

13. Chakrabarti LA: The paradox of simian immunodeficiency virus infection in sooty mangabeys: active viral replication without disease progression. Front Biosci 2004, 9:52 I-539.

14. Silvestri G, Fedanov A, Germon S, Kozyr N, Kaiser WJ, Garber DA, McClure H, Feinberg MB, Staprans SI: Divergent host responses 
during primary simian immunodeficiency virus SIVsm infection of natural sooty mangabey and nonnatural rhesus macaque hosts. J Virol 2005, 79:4043-4054.

15. Hirsch VM, Edmondson P, Murphey-Corb M, Arbeille B, Johnson PR, Mullins JI: SIV adaptation to human cells. Nature 1989, 341:573-574.

16. Kodama T, Wooley DP, Naidu YM, Kestler HW, Daniel MD, Li Y, Desrosiers RC: Significance of premature stop codons in env of simian immunodeficiency virus. J Virol 1989, 63:4709-47|4.

17. Luciw PA, Shaw KE, Unger RE, Planelles V, Stout MW, Lackner JE, Pratt-Lowe E, Leung NJ, Banapour B, Marthas ML: Genetic and biological comparisons of pathogenic and nonpathogenic molecular clones of simian immunodeficiency virus (SIVmac). AIDS Res Hum Retroviruses 1992, 8:395-402.

18. Vzorov AN, Compans RW: Effect of the cytoplasmic domain of the simian immunodeficiency virus envelope protein on incorporation of heterologous envelope proteins and sensitivity to neutralization. I Virol 2000, 74:82/9-8225.

19. Marthas ML, Banapour B, Sutjipto S, Siegel ME, Marx PA, Gardner MB, Pedersen NC, Luciw PA: Rhesus macaques inoculated with molecularly cloned simian immunodeficiency virus. J Med Primatol 1989, 18:31I-319.

20. Zerhouni B, Nelson JA, Saha K: Isolation of CD4-independent primary human immunodeficiency virus type $I$ isolates that are syncytium inducing and acutely cytopathic for CD8+ lymphocytes. J Virol 2004, 78: 1243-I 255.

21. Nguyen DH, Hildreth JE: Evidence for budding of human immunodeficiency virus type I selectively from glycolipid-enriched membrane lipid rafts. J Virol 2000, 74:3264-3272.

22. Graham DR, Chertova E, Hilburn JM, Arthur LO, Hildreth JE: Cholesterol depletion of human immunodeficiency virus type I and simian immunodeficiency virus with beta-cyclodextrin inactivates and permeabilizes the virions: evidence for virion-associated lipid rafts. J Virol 2003, 77:8237-8248.

23. Nguyen DG, Booth A, Gould SJ, Hildreth JE: Evidence that HIV budding in primary macrophages occurs through the exosome release pathway. A Biol Chem 2003, 278:52347-52354.

24. Banapour B, Marthas ML, Munn RJ, Luciw PA: In vitro macrophage tropism of pathogenic and nonpathogenic molecular clones of simian immunodeficiency virus (SIVmac). Virology I99I, 183:12-19.

25. Vzorov AN, Gernert KM, Compans RW: Multiple domains of the SIV Env protein determine virus replication efficiency and neutralization sensitivity. Virology 2005, 332:89-10I.

26. Chen Z, Zhou P, Ho DD, Landau NR, Marx PA: Genetically divergent strains of simian immunodeficiency virus use CCR5 as a coreceptor for entry. J Virol 1997, 7 1:2705-27।4.

27. Smith $A E$, Helenius $A$ : How viruses enter animal cells. Science 2004, 304:237-242.

28. Bukrinskaya A, Brichacek B, Mann A, Stevenson M: Establishment of a functional human immunodeficiency virus type I (HIVI) reverse transcription complex involves the cytoskeleton. J Exp Med 1998, 188:21 I3-2125.

29. Kimpton J, Emerman M: Detection of replication-competent and pseudotyped human immunodeficiency virus with a sensitive cell line on the basis of activation of an integrated betagalactosidase gene. J Virol 1992, 66:2232-2239.

30. Huberman JA: New views of the biochemistry of eucaryotic DNA replication revealed by aphidicolin, an unusual inhibitor of DNA polymerase alpha. Cell I98I, 23:647-648.

31. Luciw PA, Shaw KE, Unger RE, Planelles V, Stout MW, Lackner JE, Pratt-Lowe E, Leung NJ, Banapour B, Marthas ML: Genetic and biological comparisons of pathogenic and nonpathogenic molecular clones of simian immunodeficiency virus (SIVmac). AIDS Res Hum Retroviruses 1992, 8:395-402.

32. Yang $C$, Spies CP, Compans RW: The human and simian immunodeficiency virus envelope glycoprotein transmembrane subunits are palmitoylated. Proc Natl Acad Sci USA 1995, 92:987I-9875

33. Grewe C, Beck A, Gelderblom HR: HIV: early virus-cell interactions. J Acquir Immune Defic Syndr 1990, 3:965-974.

34. Maréchal V, Clavel F, Heard JM, Schwartz O: Cytosolic Gag p24 as an index of productive entry of human immunodeficiency virus type I. J Virol 1998, 72:2208-22I2.
35. Lewis $\mathrm{P}$, Hensel $\mathrm{M}$, Emerman $\mathrm{M}$ : Human immunodeficiency virus infection of cells arrested in the cell cycle. EMBO J 1992, I I:3053-3058.

36. Schmidtmayerova $\mathrm{H}$, Alfano M, Nuovo G, Bukrinsky M: Human immunodeficiency virus type I T-lymphotropic strains enter macrophages via a CD4- and CXCR4-mediated pathway: replication is restricted at a postentry level. J Virol 1998, 72:4633-4642.

37. Kim SS, You XJ, Harmon ME, Overbaugh J, Fan H: Use of helperfree replication-defective simian immunodeficiency virusbased vectors to study macrophage and $T$ tropism: evidence for distinct levels of restriction in primary macrophages and a T-cell line. J Virol 200I, 75:2288-2300.

38. Chan WE, Lin $\mathrm{HH}$, Chen : Wild-type-like viral replication potential of human immunodeficiency virus type I envelope mutants lacking palmitoylation signals. J Virol 2005, 79:8374-8387.

39. Rousso I, Mixon MB, Chen BK, Kim PS: Palmitoylation of the HIVI envelope glycoprotein is critical for viral infectivity. Proc Natl Acad Sci USA 2000, 97:13523-13525.

40. Higuchi M, Izumi KM, Kieff E: Epstein-Barr virus latent-infection membrane proteins are palmitoylated and raft-associated: protein I binds to the cytoskeleton through TNF receptor cytoplasmic factors. Proc Natl Acad Sci USA 200I, 98:4675-4680.

4I. Brown DA, Rose JK: Sorting of GPI-anchored proteins to glycolipid-enriched membrane subdomains during transport to the apical cell surface. Cell 1992, 68:533-544.

42. Bhattacharya J, Peters PJ, Clapham PR: Human immunodeficiency virus type I envelope glycoproteins that lack cytoplasmic domain cysteines: impact on association with membrane lipid rafts and incorporation onto budding virus particles. I Virol 2004, 78:5500-5506

43. Stoye JP: An intracellular block to primate lentivirus replication. Proc Natl Acad Sci USA 2002, 99: I I549-I I55 I.

44. Stremlau M, Owens CM, Perron MJ, Kiessling M, Autissier P, Sodroski J: The cytoplasmic body component TRIM5alpha restricts HIV-I infection in Old World monkeys. Nature 2004, 427:848-853.

45. Spies CP, Ritter GD Jr, Mulligan MJ, Compans RW: Truncation of the cytoplasmic domain of the simian immunodeficiency virus envelope glycoprotein alters the conformation of the external domain. J Virol 1994, 68:585-59I.

46. Guyader M, Kiyokawa E, Abrami L, Turelli P, Trono D: Role for human immunodeficiency virus type I membrane cholesterol in viral internalization. / Virol 2002, 76:10356-10364.

47. Puffer BA, Pohlmann S, Edinger AL, Carlin D, Sanchez MD, Reitter J, Watry DD, Fox HS, Desrosiers RC, Doms RW: CD4 independence of simian immunodeficiency virus Envs is associated with macrophage tropism, neutralization sensitivity, and attenuated pathogenicity. J Virol 2002, 76:2595-2605.

48. Marthas ML, Sutjipto S, Higgins J, Lohman B, Torten J, Luciw PA, Marx PA, Pedersen NC: Immunization with a live, attenuated simian immunodeficiency virus (SIV) prevents early disease but not infection in rhesus macaques challenged with pathogenic SIV. J Virol 1990, 64:3694-3700.

49. Fackler OT, Peterlin BM: Endocytic entry of HIV-I. Curr Biol 2000, 10:1005-1008.

50. Sharova N, Swingler C, Sharkey M, Stevenson M: Macrophages archive HIV-I virions for dissemination in trans. EMBO J 2005, 24:248I-2489.

51. Jolly C, Mitar I, Sattentau Q]: Requirement for an intact $\mathbf{T}$ cell actin and tubulin cytoskeleton for efficient assembly and spread of human immunodeficiency virus type I. J Virol 2007, 8I:5547-5560.

52. Nisole S, Krust B, Hovanessian AG: Anchorage of HIV on permissive cells leads to coaggregation of viral particles with surface nucleolin at membrane raft microdomains. Exp Cell Res 2002, 276: $155-173$.

53. Vzorov AN, Bhattacharyya D, Marzilli LG, Compans RW: Prevention of HIV-I infection by platinum triazines. Antiviral Res 2005, 65:57-67.

54. Derdeyn CA, Decker JM, Sfakianos JN, Wu X, O'Brien WA, Ratner L, Kappes JC, Shaw GM, Hunter E: Sensitivity of HIV type I to the fusion inhibitor T-20 is modulated by coreceptor specificity defined by the V3 loop of gp I 20. J Virol 2000, 74:8358-8367. 
55. Marozsan AJ, Fraundorf E, Abraha A, Baird H, Moore D, Troyer R, Nankja I, Arts EJ: Relationships between infectious titer, capsid protein levels, and reverse transcriptase activities of diverse human immunodeficiency virus type I isolates. J Virol 2004, 78: III30-III4I.

56. Coffin JM, Hughes SH, Varmus HE: Retroviruses. Cold Spring Harbor Laboratory Press Plainview, N.Y.; 1997.

57. Bukrinsky MI, Sharova N, Dempsey MP, Stanwick TL, Bukrinskaya AG, Haggerty S, Stevenson M: Active nuclear import of human immunodeficiency virus type I preintegration complexes. Proc Natl Acad Sci USA 1992, 89:6580-6584.

58. Blasco R, Moss B: Selection of recombinant vaccinia viruses on the basis of plaque formation. Gene 1995, 158:157-162.

59. Chackerian B, Haigwood NL, Overbaugh J: Characterization of a CD4-expressing macaque cell line that can detect virus after a single replication cycle and can be infected by diverse simian immunodeficiency virus isolates. Virology 1995, 213:386-394.

60. Désiré N, Dehée A, Schneider V, Jacomet C, Goujon C, Girard PM, Rozenbaum W, Nicolas JC: Quantification of human immunodeficiency virus type I proviral load by a TaqMan real-time PCR assay. J Clin Microbiol 200I, 39:1303-1310.

61. Abel K, Alegria-Hartman MJ, Zanotto K, McChesney MB, Marthas ML, Miller CJ: Anatomic site and immune function correlate with relative cytokine mRNA expression levels in lymphoid tissues of normal rhesus macaques. Cytokine 2001, 16:19|-204.

62. Hofmann-Lehmann R, Williams AL, Swenerton RK, Li PL, Rasmussen RA, Chenine AL, McClure HM, Ruprecht RM: Quantitation of simian cytokine and beta-chemokine mRNAs, using real-time reverse transcriptase-polymerase chain reaction: variations in expression during chronic primate lentivirus infection. AIDS Res Hum Retroviruses 2002, 18:627-639.

63. Li M, Yang C, Tong S, Weidmann A, Compans RW: Palmitoylation of the murine leukemia virus envelope protein is critical for lipid raft association and surface expression. J Virol 2002, 76: I I845-11852.

64. Regier DA, Desrosiers RC: The complete nucleotide sequence of a pathogenic molecular clone of simian immunodeficiency virus. AIDS Res Hum Retroviruses 1990, 6:|22I-I23I.

\section{Publish with Bio Med Central and every scientist can read your work free of charge}

"BioMed Central will be the most significant development for disseminating the results of biomedical research in our lifetime. "

Sir Paul Nurse, Cancer Research UK

Your research papers will be:

- available free of charge to the entire biomedical community

- peer reviewed and published immediately upon acceptance

- cited in PubMed and archived on PubMed Central

- yours - you keep the copyright

Submit your manuscript here:

http://www.biomedcentral.com/info/publishing_adv.asp
BioMedcentral 